\title{
ALLGEMEINE VOLKSWIRTSCHAFTSLEHRE
}

\author{
III \\ PRODUKTIONSFAKTOREN \\ von \\ DR. A N D EAS PAULSEN \\ o. Professor an der Freien Universität Berlin
}

3., neubearb. und ergänzte Auflage

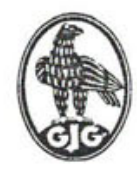

WALTER DE GRUYTER \& CO. vormals G. J. Gøschen'sche Verlagshandlung - J. Guttentag, Verlegsbachhandlung - Georg Reimer - Karl J. Trubner - Veit \& Comp. BERLIN 1963 
Die Gesamtdarstellung umfaßt folgende Bände:

Band I: Grundlegung, Wirtschaftskreislauf

(Sammlung Göschen Band 1169)

Band II: Haushalte, Unternehmungen, Marktformen

(Sammlung Göschen Band 1170)

Band III: Produktionsfaktoren

(Sammlung Göschen Band 1171)

Band IV: Gesamtbeschäftigung, Konjunkturen, Wachstum (Sammlung Göschen Band 1172)

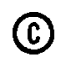

Copyright 1963 by Walter de Gruyter \& Co., vormals G. J. Göschen'sche Verlagshandlung - J. Guttentag Verlagsbuchhandlung - Georg Reimer - Karl J. Trübner - Veit \& Comp., Berlin 30. - Alle Rechte, einschl. der Rechte der Herstellung von Photokopien und Mikrofilmen, vom Verlag vorbehalten. - Archiv-Nr. 7520632 - Satz und Drudk: Paul Funk, Berlin 30. - Printed in Germany. 